\title{
El marxismo y la burocracia sindical. La experiencia alemana (1898-1920)
}

\author{
Constanza Bosch Alessio y Daniel Gaido \\ (UNC y UNC-CONICET)
}

\section{Los marxistas "ortodoxos" y los sindicatos}

Ya desde la controversia revisionista de 1898-1903, Rosa Luxemburg llevó adelante una polémica constante con los funcionarios de los sindicatos alemanes "Libres" (es decir, socialdemócratas). En su folleto de 1899 contra Eduard Bernstein, ¿Reforma social o revolución?, Luxemburg escribió un pasaje ya célebre, señalando que "las condiciones objetivas de la sociedad capitalista transforman las dos funciones económicas de los sindicatos [la defensa de la fuerza de trabajo (como mercancía) contra el sistema social basado en la ganancia, y la mejora de las condiciones de vida de los trabajadores] en un trabajo de Sísifo" (Luxemburg, 1970). Kautsky apoyó este punto de vista, por ejemplo en su artículo de 1906, "El Partido y los sindicatos", donde escribió que, a diferencia del objetivo final del Partido Socialdemócrata, "el trabajo sindical, indispensable y beneficioso como es, puede equipararse al trabajo de Sísifo, no en el sentido de un trabajo inútil, sino en el sentido de un trabajo que jamás concluye, y que debe ser reiniciado desde cero cada vez", a fin de preservar las conquistas obtenidas por la lucha de los sindicatos (Die Neue Zeit, 24, 2, 1906). Esta metáfora tuvo tal impacto que, en fecha tan tardía como la de 1910, la Comisión General de Sindicatos Libres de Alemania la utilizó para realizar su crítica del libro de Kautsky El camino al poder (Generalkommission der Gewerschaften Deutschands, 1910).

La Comisión General de Sindicatos Libres de Alemania (Generalkommission der Freien Gewerschaften Deutschlands), la federación de sindicatos socialdemócratas, fue fundada entre el 16 y el 17 de noviembre de 1890 por una Conferencia de Dirigentes Sindicales que tuvo lugar en Berlín. El presidente de la Comisión fue, durante treinta años, desde su fundación en 1890 hasta su desaparición en 1920, Carl Legien, un miembro del ala derecha del Partido Socialdemócrata Alemán. Legien 
tuvo una influencia capital en la política de la Comisión General en tanto editor de su periódico oficial, el Correspondenzblatt, cuyo primer número apareció en 1891. Ya en 1893, en el Congreso de Colonia del SPD (el Partido Socialdemócrata Alemán: Sozialdemokratische Partei Deutschlands), Legien sostuvo que, en su opinión, el partido y los sindicatos eran "igualmente importantes". El vocero del Ejecutivo del Partido, Ignaz Auer, lo acusó de intentar separar a los sindicatos del partido y de convertirlos en un poder rival a este. Utilizando una metáfora un tanto curiosa, Auer advirtió a Legien contra su adhesión al ejemplo del líder de la federación sindical norteamericana Samuel Gompers: "El movimiento obrero alemán", dijo, "no es la clase de terreno donde el maíz de Gompers y sus socios puede crecer" (Varain, 1956: 16). Treinta años después, en 1906, Werner Sombart establecía la misma analogía: “...el presidente de la Federación Norteamericana del Trabajo, cuyo equivalente en Alemania sería Carl Legien" (Sombart, 1976: 86).

Además de su puesto en la Comisión General, Legien ocupó una serie de importantes cargos políticos: diputado del Reichstag (1893-1898 y 1903-1920), Secretario de la Oficina Internacional de Sindicatos Socialistas (1902), y presidente de la Federación Internacional de Sindicatos (1913) (Schneider, 1991: 86).

Ya en 1900, Kautsky había hecho sonar la voz de alarma al señalar que los líderes sindicales peleaban por su independencia del partido bajo la consigna de "neutralidad" (Die Neue Zeit, 18, 2, 1900: 388-394, 429-433, 457-466, 492-497). El Correspondenzblatt respondió que "aún contra Kautsky, debemos aferrarnos a la visión de que la táctica de los sindicatos estará determinada únicamente por las resoluciones de los congresos sindicales, antes que por aquéllas formuladas en los congresos partidarios" (citado por Varain, 1956: 30).

\section{La Revolución Rusa de 1905 y el "revisionismo sindical"}

Luego del debate revisionista, formalmente ganado por la mayoría marxista "ortodoxa" del SPD, los líderes de esta corriente sintieron que sus pronósticos revolucionarios se veían confirmados por los vivificantes acontecimientos de la primera Revolución Rusa, que comenzó en el "Domingo Sangriento" (9 de enero de 1905). Todos los aspectos del pensamiento de Kautsky experimentaron una considerable radicalización bajo la influencia de Rosa Luxemburg, quien, dada la ignorancia de Kautsky del ruso, sirvió como su principal intérprete de los acontecimientos revolucionarios.

En mayo de 1905 los sindicatos congregados en la Comisión General de Sindicatos Libres de Alemania sostuvieron su quinto congreso en Colonia, donde rechazaron categóricamente la utilización de la huelga 
política de masas -una demanda inspirada fundamentalmente por los eventos revolucionarios de Rusia. El vocero de la Comisión General sobre esta cuestión, Theodor Bömelburg, presidente del Sindicato de los Trabajadores de la Construcción, atacó no sólo al ala izquierda del SPD sino también inclusive a Eduard Bernstein (quien veía en la huelga general no un medio revolucionario para superar el reformismo parlamentarista, sino un medio de defensa del parlamento y de los derechos democráticos frente a los ataques de la reacción), argumentando que "a fin de expandir nuestra organización, necesitamos paz y tranquilidad (Ruhe) en el movimiento obrero" (citado por Grunenberg, 1970: 346-354).

La resolución adoptada por el Congreso Sindical de Colonia rechazó la huelga de masas como táctica política y prohibió siquiera la "propagación" (v.gr., la propaganda o discusión) de este medio de lucha. Argumentaba además que la huelga de masas era defendida por "anarquistas y personas sin ninguna experiencia en las luchas económicas", y advertía a los trabajadores organizados "que eviten ser distraídos de su trabajo cotidiano de fortalecimiento de las organizaciones obreras por la adopción y promoción de tales ideas" (Luxemburg, 1972a).

Cuando Kautsky criticó esta resolución (Die Neue Zeit, 23, 2 1905: 309-316), el órgano central del SPD, el Vorwärts, bajo dirección de Kurt Eisner, lo acusó de ser un ideólogo doctrinario, predicador de la utopía neoanarquista de conquista del poder político a través de la huelga general. En octubre de 1905, Eisner y otros cuatro editores fueron cesanteados y un nuevo comité editorial proveniente del ala izquierda tomó el control del Vorwärts (Salvadori, 1979: 96-97).

En noviembre de 1905 Kautsky sostuvo que, justo cuando se había hecho evidente la bancarrota del revisionismo teórico y político (el ministerialismo),

ha surgido un nuevo revisionismo, el revisionismo sindical, apoyado en una parte de la burocracia sindical. Este revisionismo ha predicado, bajo la bandera de la neutralidad, un rechazo de la Socialdemocracia. No le importa la Socialdemocracia en tanto partido de la clase obrera, la concibe como un partido cualquiera. No como el partido que unifica al proletariado, sino como uno de los partidos en los que el proletariado se encuentra dividido. La Socialdemocracia ha sido vista como un factor que perturba la unidad organizacional del proletariado. Si se pretende unificar a los trabajadores católicos, conservadores y liberales con los socialdemócratas en un mismo sindicato, entonces esta unión ha de llevarse a cabo, no a través de la demostración de la utilidad y la necesidad de la Socialdemocracia, sino a través del renunciamiento por parte del sindicato 
al espíritu socialdemócrata con el que había nacido. (Die Neue Zeit, 23, 2, 1905: 309-316, subrayado en el original)

En el Congreso de Jena del SPD, llevado a cabo en septiembre de 1905, August Bebel, el dirigente histórico del SPD, criticó la hostilidad de los líderes sindicales hacia la huelga política de masas, calificándola de "sindicalismo puro y simple" (citado por Grunenberg, 1970: 356-378). Frente a la resolución del Congreso Sindical de Colonia, el Congreso de Jena adoptó una resolución apoyando la utilización de la huelga política de masas en la lucha por los derechos democráticos y electorales; sin embargo, esta medida fue descrita, ante la insistencia de Bebel, como una táctica defensiva ante el esperado asalto de la burguesía sobre las conquistas progresivas del movimiento socialista (Die Neue Zeit, 24, 1, 1905; Luxemburg, 1972b). El Correspondenzblatt rechazó aún esta versión diluida de la huelga general. Informó que "Legien llamó a la propaganda por la huelga política una inoportuna concesión a los anarquistas" agregando que, aunque "la moción de Legien y sus camaradas fue rechazada y la resolución de Bebel adoptada por 288 votos contra 14", era "imposible para el partido imponer forzosamente sus resoluciones sobre los sindicatos. La única solución factible, por lo tanto, es alcanzar un acuerdo sobre esta cuestión" (citado por Stern, 1961: 715).

Y esto es lo que finalmente sucedió: en una conferencia secreta del ejecutivo del SPD y la Comisión General, mantenida el 16 de febrero de 1906, el ejecutivo del partido abogó por "intentar evitar, en la medida de lo posible, una huelga de masas". Si ésta sin embargo se desencadenaba, el partido asumiria por sí mismo la responsabilidad de su conducción: los sindicatos no participarian oficialmente en ella, acordando únicamente "no apuñalarla por la espalda".

\section{La polémica de Kautsky con la dirección sindical}

En abril de 1906 Kautsky fue forzado a salir en defensa de Rosa Luxemburg, atacada por un órgano de prensa sindical. El Zeitschrift für Graveure und Ziseleure escribió que tenía "testigos de carne y hueso que sostenían que la camarada Luxemburg había "parloteado" en una asamblea en Berlín acerca de los sindicatos, considerándolos como «un mal»". Kautsky respondió que "no había sido la camarada Luxemburg quien socavaba las relaciones entre el partido y los sindicatos, sino aquéllos funcionarios sindicales y editores que habían tomado a Rexhäuser como modelo". Ludwig Rexhäuser era el líder del sindicato de impresores y editor de su periódico: Correspondent für Deutschlands Buchdrucker und Schriftgießer (citado por Stern, 1961: 1555-1559). Kautsky rechazó las acusaciones de los sindicatos como falsas, y agregó: 
Aún nuestros adversarios burgueses, al menos los más decentes -que ciertamente no son muchos- han evitado atacar a la camarada Luxemburg. Los órganos de la prensa sindical van de la mano en este asunto con los más infames y vergonzosos lacayos del capitalismo y con la aristocracia (Junkertum) en la prensa. (Citado por Stern, 1961: 1548-1549)

El órgano de la Comisión General, el Correspondenzblatt, consideró "chocante" la adopción de este tono por el "proclamado primer teórico del Partido" y preguntó de manera retórica si la desfachatez era el producto necesario de una educación académica (citado por Friedemann, 1978: 1550). Kautsky contestó preguntando por qué los sindicatos no fueron capaces de identificar a aquéllos presuntos "testigos de carne y hueso" opositores a Rosa Luxemburg (citado por Stern, 1961: 1555-1559).

Entre los Congresos del SPD de Jena y Mannheim, en agosto de 1906, Kautsky escribió su trabajo fundamental sobre las relaciones entre el partido político y los sindicatos, donde argumentó contra la neutralidad política de los sindicatos y demandó su subordinación al liderazgo revolucionario del partido. El artículo señalaba que, dependiendo de las circunstancias politicas, los sindicatos podrian convertirse en la élite de la clase trabajadora, o en una aristocracia estrecha de miras de trabajadores especializados organizados; es decir, en un medio para la lucha de clases o en un impedimento a esta lucha. Los sindicatos representaban los intereses económicos momentáneos de sus miembros, mientras que el partido revolucionario representaba los intereses del proletariado en su conjunto, así como la meta final de su lucha: la conquista del poder politico por parte de la clase trabajadora. Atacaba a los "sindicalistas puros" tanto como los funcionarios sindicales rechazaban a los "políticos puro". Para muchos lideres sindicales, el partido aparecía como una amenaza a su paz y tranquilidad y como el heraldo de catástrofes políticas que podrían arruinar a los sindicatos. El artículo de Kautsky denunciaba la "búsqueda de una nueva teoría sindical" entre los funcionarios de los sindicatos que se sentían constreñidos por la "teoría del partido" de la lucha de clases (Die Neue Zeit, 24, 2,1906: 718). Con la ventaja que da una mirada retrospectiva, está claro que la cálida recepción acordada cuatro años antes al evangelio del sindicalismo "puro y simple" de Samuel Gompers por parte de la Comisión General de Sindicatos Libres en general y por parte de Karl Legien en particular, no fue tanto una cuestión de un "sindicalismo de negocios" norteamericano corrompiendo a los funcionarios sindicales marxistas alemanes; se trató más bien de un funcionariado sindical alemán en abierta rebelión contra el programa del partido, buscando apoyo en los lideres sindicales de pensamiento similar al otro lado del océano. 
Kautsky recordó cómo los funcionarios sindicales ingleses en la Primera Internacional "sintieron el liderazgo de Marx como un «autoritarismo» crecientemente insoportable y no dudaron en unirse ellos mismos a los «románticos revolucionarios» de la fracción Bakunin, tan pronto como la tendencia de Marx al establecimiento en Inglaterra de un partido político independiente de los trabajadores se volvió clara". Y lo hicieron debido a que "sintieron instintivamente que esto hubiese sido crear un poder que habria puesto fin a su dominio autocrático. De la misma manera, no existen en los Estados Unidos enemigos más venenosos del Partido Socialdemócrata que las masas de los funcionarios sindicales, con Gompers a la cabeza" (Die Neue Zeit, 24, 2,1906: 750).

De manera interesante, en su respuesta al artículo de Kautsky el Correspondenzblatt señaló correctamente que "la lucha de Kautsky no está dirigida contra las organizaciones sindicales, sino contra los lideres y editores sindicales... a fin de socavar la confianza de los miembros de los sindicatos en los lideres de sus organizaciones" (citado por Friedemann, 1978: 527, subrayado en el original).

\section{E1 Congreso de Mannheim del SPD (1906)}

La polémica continuó en el congreso del SPD sostenido en septiembre de 1906 en Mannheim. En su discurso al congreso, Kautsky planteó abiertamente la cuestión de la burocratización creciente del propio partido y llamó la atención sobre el peligro de la formación de un bloque conservador entre el aparato del partido y los aparatos sindicales:

Si ahora los sindicatos quieren paz y tranquilidad, qué perspectivas se abren para nosotros si éstos se unen al ya voluminoso aparato del partido, incrementando así su inercia. (Citado por Stern, 1961)

Kautsky comparó la falta de disciplina partidaria de los funcionarios sindicales con la de los miembros parlamentarios socialistas franceses. Legien, a su vez, señaló que los anarquistas habían considerado la resolución de Jena como una adopción culposa de sus propias ideas sobre la huelga general, y que, aún dentro de las filas de la Socialdemocracia, mucha gente había entendido a partir de ella que el partido estaba listo para utilizar la huelga politica de masas en el futuro cercano, en especial para obtener el sufragio general en Prusia. Frente a esta actitud, Legien recordó que "por más de dos décadas, nosotros en Alemania fuimos educados en la concepción de Auer de que la «huelga general es un sinsentido general»". Legien enfatizó las tácticas reformistas del SPD: "En el partido se enseñó por diez años que las revoluciones en el 
viejo sentido no son ya posibles. Siempre hemos dicho que prosperamos mejor en el marco de la legalidad. Hemos dicho una y otra vez que podemos organizar una resistencia no violenta". Concluyó: "Considero peligrosa la discusión sobre la huelga politica de masas" (citado por Grunenberg, 1970: 402).

\section{E1 panfleto de Rosa Luxemburg sobre la huelga de masas}

Fue en reacción a esta actitud en los círculos principales de los sindicatos Socialdemócratas alemanes que Rosa Luxemburg publicó, en el mismo mes en que tuvo lugar el congreso de Mannheim (septiembre de 1906), su famoso folleto La huelga de masas, el partido politico y los sindicatos, en el que defendía la idea de la huelga política de masas como lección fundamental de la primera Revolución Rusa para la clase obrera alemana, sopesando la iniciativa revolucionaria espontánea de las masas trabajadoras frente a las politicas conservadoras de los líderes obreros (acerca del congreso de Mannheim, ver Luxemburg, 1972b).

La resolución del congreso de Mannheim, cuyo borrador fue nuevamente redactado por Bebel, representó una victoria histórica de la burocracia sindical ante los revolucionarios en el SPD. Aunque no rechazaba a la huelga general en principio, la resolución de Mannheim establecía que el ejecutivo del partido no podría llevar a cabo acciones sin la aprobación de los sindicatos, dándoles así a éstos efectivamente un poder de veto sobre las decisiones del partido. El periódico radical Leipziger Volkszeitung sacó de la resolución del congreso de Mannheim la amarga conclusión de que diez años de lucha contra el revisionismo habian sido en vano, "ya que el revisionismo que hemos aniquilado en el partido se eleva de nuevo con gran fuerza en los sindicatos" (Schorske, 1970: 52).

Kautsky se engañó a sí mismo al pensar que, en lo relativo a "la cuestión central de la conferencia, la relación entre el partido y los sindicatos", los resultados de la conferencia de Mannheim habian sido satisfactorios, ya que "los líderes sindicales aceptaron los puntos de vista del partido sobre las cuestiones del Primero de Mayo y de la huelga de masas" - soslayando, de hecho, la contradicción entre las resoluciones de Jena y Colonia. Pero Kautsky reconoció que "el discurso de Bebel en Mannheim dio la impresión de representar un paso atrás en comparación con el Congreso de Jena, como si él considerara hoy que la posibilidad de aplicación de la huelga general en Alemania es mucho más remota que un año atrás". Kautsky concluyó que "el congreso del partido en Dresden significó el fin del revisionismo teórico, aunque nuestros adversarios ponen grandes expectativas en el «revisionismo práctico» de los sindicalistas" (Die Neue Zeit, 25, 2, 3,1906: 4-10). 
La capacidad de los líderes sindicales para imponer su linea al SPD derivó de dos fuentes principales: la gran cantidad de miembro de los sindicatos y sus aún mayores recursos financieros en comparación con los del partido. De 215.000 miembros en 1892, la afiliación de los Sindicatos Libres Socialdemócratas creció a más de 1 millón cien mil en 1904, y a 2 millones y medio el año anterior al estallido de la Primera Guerra Mundial, dejando atrás a los sindicatos liberales de HirschDuncker y a los sindicatos cristianos con, respectivamente, 106.000 y 218.000 miembros en 1913 (Schneider, 1991: 70,75). En 1906, cuando el SPD realizó su primer censo, resultó que su afiliación era de 348.327 personas, contra 1.689.709 de los Sindicatos Libres. En 1913, la relación era aún de dos y medio a uno a favor de los sindicatos. Además, el ingreso del partido durante el año fiscal 1906-1907 fue de 1.191.819 marcos; el de los sindicatos, de 51.396 .784 marcos - es decir, cerca de cincuenta veces más (Schorske, 1970: 13, 93). De manera nada sorprendente, la proporción de funcionarios sindicales en la bancada del SPD en el Reichstag creció del 11,6\% en 1893, al 32,7\% en 1912 (Schneider, 1991: 92).

\section{La polémica de Kautsky con la dirección sindical norteamericana}

En mayo de 1909, Kautsky publicó su libro El camino al poder, que fue considerado por Lenin como "el último y mejor de los trabajos de Kautsky contra los oportunistas" (Kipnis, 1952: 342).Utilizando estadísticas de la Oficina del Trabajo de los Estados Unidos, Kautsky argumentaba que, a pesar de todas las luchas industriales de los trabajadores norteamericanos, el poder adquisitivo de los salarios en los Estados Unidos se encontraba estancado desde hacía más de una década debido especialmente al crecimiento de los trusts y asociaciones patronales. Los sindicatos se verian, de este modo, obligados a ingresar a la arena política y a entrar en estrecha colaboración con el Partido Socialista, si es que deseaban estar en condiciones de soportar la presión de la patronal y de defender los niveles de vida de sus afiliados (Kautsky, 1909). Este análisis condujo a un violento intercambio con los órganos de prensa de la derecha sindicalista del SPD, en especial con el Grundstein y el Correspondenzblatt, que acusó a Kautsky de ser

1. "Lenin consideraba a Kautsky como su maestro, cuestión que remarcaba cada vez que podía. Hablando sobre el menchevismo como ala oportunista de la Socialdemocracia, Lenin comparó a los mencheviques no con el kautskismo, sino con el revisionismo. Más aún, consideraba al bolchevismo como la apariencia rusa del kautskismo que, desde su mirada en aquel período, era idéntico al marxismo" (Trotsky, 1973:132). 
"un oponente de la organización sindicalista" que "menospreciaba e infravaloraba" el trabajo de los sindicatos. Robert Schmidt escribió una serie de artículos en el Correspondenzblatt, bajo el título de "El camino a las ilusiones: ¿trabajo de Sísifo o logros positivos?," que acusaba a Kautsky de querer transformar "las conquistas previas de los sindicatos en fracasos futuros" y de estar "muy poco calificado para mostrarnos el camino al poder" (citado por Varain, 1956: 63). El Correspondenzblatt alabó el éxito de los sindicatos norteamericanos en el acortamiento de la jornada laboral en casi un 5 por ciento desde 1898 hasta 1907 y acusó a Kautsky de anarcosindicalismo: "A Kautsky no le importa la evolución de los sindicatos como organizaciones económicas poderosas... No tiene en mente otra cosa que el [anarco]sindicalismo francés" (Correspondenzblatt, 1909: 626).

Kautsky respondió a las acusaciones del Correspondenzblatt sosteniendo que las luchas industriales podian elevar los salarios en un momento dado, pero que no determinan su evolución en el largo plazo, la cual depende de procesos económicos más profundos. Dada una tendencia alcista, los sindicatos podrian acelerar la suba de los salarios; dada una tendencia a la baja, podían desacelerar su disminución. Pero los sindicatos no podían controlar estas tendencias a voluntad, como sostenían los reformistas. Los sindicatos eran capaces "de mantener los salarios en un nivel relativamente más alto del que éstos habrian de otro modo de alcanzar, pero no pueden garantizar una suba ininterrumpida de los salarios en términos absolutos" (Die Neue Zeit, 27, 2, 1909: 523). Si deseaban estar capacitados para hacer frente al poder concentrado de los capitalistas y de su Estado, estaban obligados a politizarse cada vez más y a estar preparados para utilizar su arma más poderosa, la huelga política de masas. Kautsky confiaba en que, al igual que en los casos de Gran Bretaña y Austria, también en Alemania "las grandes luchas hacia las que marchamos unificarán estrechamente al partido y los sindicatos convirtiéndolos en una poderosa falange, cuyas partes no se entorpecerán mutuamente; por el contrario, se alentarán y fortalecerán la una a la otra para la pelea". Su objetivo al redactar El camino al poder había sido el de "alentar este proceso, destacando esos grandes logros que sólo pueden ser conseguidos a través de una lucha en común por parte del partido y los sindicatos y acentuando la creciente impotencia a la cual el aislamiento condenará a ambos", pero sus argumentos habían desatado una tormenta de controversias por parte de sus críticos del Correspondenzblatt. Kautsky los acuso de "haberse alineado junto a Rexhäuser y Gompers" (Die Neue Zeit, 27, 2, 1909: 832).

La polémica de Kautsky con la dirección sindical alemana en torno a las estadísticas norteamericanas se agudizó en ocasión de la visita de Samuel Gompers, el líder de la Federación Norteamericana del Trabajo 
(AFL) a mediados de 1909. Para ese entonces, la AFL tenía más de un millón y medio de afiliados en Europa y Alemania.

\section{Samuel Gompers y la Federación Norteamericana del Trabajo (AFL)}

Samuel Gompers fue presidente de la Federación Norteamericana del Trabajo (AFL) ${ }^{2}$ desde su fundación en 1886 hasta su muerte, en 1924, con la excepción de un único año, 1894, cuando fue temporalmente derrotado por el candidato populista John McBride. Inicialmente un discípulo de los marxistas germano-estadounidenses, Gompers se volvió cada vez más conservador hacia finales del siglo diecinueve. Gradualmente, Gompers comenzó a oponerse también al sindicalismo industrial y a la formación de un partido de los trabajadores, para terminar aceptando políticas racistas y apoyando a la nueva política exterior imperialista inaugurada por la guerra hispano-norteamericana de 1898. Gompers se declaró públicamente contra el socialismo en la convención de 1903 de la AFL.

El pánico de 1893, una de las peores crisis económicas en la historia de los Estados Unidos, y la ola de militancia obrera resultante, dieron origen a la creación en 1900 de la Federación Cívica Nacional $(\mathrm{NCF})$, una institución que promovia la colaboración de clases. Gompers se unió a la nueva organización en calidad de vicepresidente y, como tal, apoyó la posición de los empleadores contra los sindicatos en dos huelgas en las cuales el empleador era a la vez Presidente del Departamento Industrial de la NCF. La NCF se opuso no sólo al socialismo sino al sufragio femenino. Luego de la Primera Guerra Mundial, militó en contra del reconocimiento diplomático de la Unión Soviética, y luchó contra las jubilaciones estatales, considerándolas "socialistas". Después de la represión desatada por la histeria anticomunista que siguió a la Revolución Bolchevique, la NCF entró en decadencia.

El 31 de julio de 1909 se celebró en Berlín una reunión en honor de Gompers. Fue en este marco en el cual Kautsky publicó, el 13 de agosto de 1909, el artículo contra Gompers. La crítica de Gompers escrita por Kautsky era una proyección de la lucha contra la burocracia sindical alemana llevada a cabo por el ala revolucionaria de la Socialdemocracia. Posteriormente, las criticas de Lenin al liderazgo sindical alemán habrian de retomar las de Kautsky (ver, por ejemplo, su artículo sobre Legien: Lenin, 1970).

2. La AFL fue instituida como una asociación de sindicatos estadounidenses en 1886. 
En su artículo contra Gompers, Kautsky argumentaba que el entonces presidente de la AFL representaba no sólo un opositor al socialismo en Estados Unidos, sino también un enemigo de la clase proletaria en general. A fines de refutar el concepto de armonía de intereses entre capital y trabajo que Gompers defendia, Kautsky demostró que la calidad de vida de la clase obrera estadounidense habia declinado, mientras que la de los trabajadores alemanes había mejorado: "Precisamente durante la década en la cual el movimiento obrero norteamericano estuvo dominado por el señor Gompers, la mejora en la situación de la clase trabajadora norteamericana se ha estancado" (citado por Gaido, 2007: 46). Kautsky sostenía que Gompers necesitaba engañar a los trabajadores europeos para continuar engañando a los estadounidenses, ya que especulaba con aprovechar el apoyo que obtendría del proletariado europeo -fruto de su internacionalismo-, para transformarlo, tras su regreso a Estados Unidos, en defensa de la armonía entre el capital y el trabajo y en descrédito hacia los socialdemócratas norteamericanos. Kaustky concluía alertando a los trabajadores que sólo dispondrían de poder político en su propio partido y que cada aplauso hacia Gompers constituía una verdadera "bofetada en la cara de nuestro partido hermano estadounidense, el cual no tiene enemigo más peligroso y venenoso que Samuel Gompers".

Dos meses y medio después de la publicación de su artículo sobre Gompers, Kautsky redactó una secuela al mismo titulada "La Federación Cívica", donde defendía al órgano principal de la sección alemana del Partido Socialista de Norteamérica. El New Yorker Volkszeitung habia sido acusado por el Correspondenzblatt de abogar por una división en las filas de la AFL. Kautsky respondió citando un artículo del New Yorker Volkszeitung donde los editores negaban que la publicación apoyase "cualquier movimiento en particular contra la Federación, dado que para nosotros la unidad de la organización sindical de nuestro país está por sobre cualquier otra cosa". Los editores del New Yorker Volkszeitung admitían que combatían "contra el espíritu gompersiano de la Federación, pero la AFL en tanto unidad del movimiento sindical norteamericano no cuenta con partidario más firme que nuestro periódico" (Die Neue Zeit, 28, 1, 1910: 132-137). Kautsky concluia calificando a la Federación Cívica como "una banda de nuestros más sucios y encarnizados enemigos", y se preguntaba cómo Legien puede considerarse a sí mismo un amigo de Gompers (Vorwärts, 256, 2, 1909: 137). Por más de tres meses la controversia sobre Gompers y la Federación Cívica Nacional continuó llenando las páginas de la prensa socialdemócrata alemana (Die Neue Zeit, 28, 1, 1910: 253-254; Correspondenzblatt, 1909).

El viaje europeo de Gompers fue retribuido tres años más tarde, cuando Carl Legien hizo un viaje de tres meses a Estados Unidos. Legien 
escribió un libro sobre sus experiencias en América, en el cual argumentó que "no debe hablarse de un funcionariado corrupto en los sindicatos americanos, como se hace a menudo" (Legien, 1914: 151-153).

\section{Los sindicatos y la escisión entre el ala izquierda y el centro del SPD (1910)}

El artículo de Kautsky contra Gompers fue el canto de sirena de su carrera revolucionaria. Como hemos podido ver, el temor tradicional de los líderes del SPD había sido que Legien y sus compañeros funcionarios sindicales se separaran del partido y que, bajo la bandera de la neutralidad política, transformaran a la Comisión General en un poder independiente y opuesto a él. El desarrollo histórico concreto resultó en proceso exactamente opuesto. Luego de emprender una guerra de desgaste contra el ala revolucionaria del partido y contra la idea de la huelga general política por más de una década, la burocratización creciente del propio partido creó una comunidad de intereses entre el liderazgo sindical y la mayor parte de los 4.000 funcionarios rentados partidarios, de manera que las posiciones reformistas de los sindicatos llegaron a controlar el Ejecutivo del partido, convirtiendo así a los funcionarios sindicales en promotores de la disciplina y la unidad partidarias y al ala izquierda del SPD en defensora eventual de una escisión en el Partido Socialdemócrata. Si este proceso no fue advertido por muchos observadores cercanos del SPD, como Lenin y Trotsky, eso se debió en gran medida al papel jugado por Kautsky desde 1910, cuando éste rompió con Rosa Luxemburg para convertirse en el ideólogo principal de la fracción de "centro" dominante en el SPD.

En fecha tan tardía como la del 26 de septiembre de 1909, Kautsky se quejaba en una carta dirigida a Víctor Adler del "crecimiento excesivo del burocratismo, el cual corta de raíz cualquier iniciativa y acto de audacia". Kautsky creía que "sólo cuando la acción venga de las masas será posible contar con el impetu y entusiasmo necesario" pero que "en Alemania las masas han sido instruidas para esperar órdenes de arriba" y que la dirigencia había sido "tan absorbida por las necesidades administrativas del enorme aparato, que ha perdido toda perspectiva general, todo interés por cualquier asunto que esté fuera de los asuntos del propio funcionariado. Nosotros lo hemos visto primero en los sindicatos, ahora lo vemos también en la organización política" (Adler, 1954: 501).

Pero cinco meses más tarde, bajo presión del aparato partidario cuyo creciente conservadurismo él había señalado, Kautsky rechazó publicar un artículo de Rosa Luxemburg en el cual la revolucionaria polaca llamaba a la huelga general con el fin de alcanzar el sufragio universal 
en Prusia y planteaba el slogan de la república como demanda de transición, con el objeto de convertir el problema de la reforma electoral en un canal para la acción revolucionaria. Esto resultó en un furioso round de polémicas, en el curso de las cuales Kautsky se convirtió en el teórico principal de los centristas del SPD, desarrollando la así llamada "estrategia del desgaste", en oposición a la "estrategia de derrota" del enemigo sostenida por Rosa Luxemburg (Die Neue Zeit, 28, 2, 1910: 332-341, 364-374, 412-421; Luxemburg 1973c; Die Neue Zeit, 28, 2, 1910: 652-667; Luxemburg, 1973d).

De acuerdo con su mejor biógrafo, Marek Waldenberg, Kautsky consideró que el aspecto positivo de su polémica con Rosa Luxemburg era la posibilidad de tomar cierta distancia de su imagen extremadamente impopular en el entorno de la burocracia sindical (Waldenberg, 1980: 673-674). En una carta dirigida a Riazanov, fechada el 16 de junio de 1910, Kautsky escribió que las posiciones de Rosa Luxemburg sobre la huelga general suscitaron un gran antagonismo entre los líderes sindicales:

Me irritó que mi influencia entre los sindicalistas esté paralizada por el hecho de que he sido confundido con Rosa. Me parece que, a fin de entablar buenas relaciones entre los marxistas y los sindicalistas, es importante mostrar que sobre este punto existe una gran distancia entre Rosa y yo. Esta es para mí la cuestión más importante. (Citado por Laschitza, 1969: 264 y Waldenberg, 1980: 673)

Sin embargo, las esperanzas de Kautsky de congraciarse con la derecha sindicalista para ganar su apoyo, de manera que el liderazgo del SPD permaneciera en manos de la fracción de centro, terminaron en el fracaso. Al interior del propio partido, el poder estaba cambiando rápidamente de mano, desde el "centro" kautskista a la derecha chauvinista y abiertamente reformista. En palabras de Zinoviev, al momento del Congreso de la Internacional Socialista de Copenhague (del 28 de agosto al 3 de septiembre de 1910):

los oportunistas (es decir, los futuros social-patriotas) tenían la mayoría en la Socialdemocracia Alemana (...) los verdaderos amos eran ya no [el centrista] Ledebour o aún Bebel, sino Legien, Sudekum y David. (Zinoviev, 1970: 232)

El giro a la derecha en el Ejecutivo del Partido fue tan marcado que "Legien podría declarar en el congreso sindical de 1911 que no había diferencias con el partido, sino con algunos escritores individuales del 
partido" (Varain, 1956: 62). Esta amalgama del partido y las burocracias sindicales allanó el camino para la debacle del 4 de agosto de 1914 -momento en que la fracción del SPD en el Reichstag votó a favor de los créditos de guerra- y para el colapso de la Segunda Internacional como una organización revolucionaria de la clase trabajadora.

\section{La traición (1914-1920)}

El 2 de agosto de 1914, ante el estallido de la Primera Guerra Mundial, los sindicatos suscribieron con la patronal un acuerdo prescribiendo huelgas y lock-outs y prolongando todos los convenios colectivos mientras durasen las hostilidades (Broué, 2005: 46). Resulta significativo el hecho de que los sindicatos actuaran incluso con anticipación al partido a la hora de neutralizar la oposición al Estado y a la patronal. Luego de haber aprobado los créditos de guerra, el SPD abandonó el eslogan que lo caracterizaba -"a este sistema, ni un hombre ni un penique"- por el de "a la hora del peligro, no traicionaremos a la patria" Schorske, 1970: 285).

La Primera Guerra Mundial generó una ola de patriotismo que fue aprovechada por el régimen para proclamar la suspensión voluntaria de todos los enfrentamientos políticos entre los partidos o contra el gobierno, conocida como la "tregua" (Burgfrieden). Los líderes del movimiento obrero asumieron la tarea de disciplinar al proletariado, a los fines de someterlo a los intereses del Estado. De acuerdo a Carl Schorske, suscribir a la Burgfrieden tuvo tres efectos principales sobre el movimiento obrero alemán: en primer lugar, acortó la brecha psicológica entre los líderes sindicales y los grupos dominantes; en segundo lugar, acrecentó la importancia de los dirigentes del movimiento, al confinar la acción política y económica exclusivamente a la esfera de la negociación; y, por último, obligó al SPD a tomar definitivamente un curso reformista (Schorske, 1970: 293-294).

En este contexto, el ala izquierda del SPD, aislada, mantenía las esperanzas de devolverle al partido su rol opositor al gobierno. El 2 de diciembre de 1914 sólo Karl Liebknecht votó en contra de la aprobación de nuevos créditos de guerra, quebrando la disciplina partidaria. Fue ampliamente atacado en el seno del partido, puesto que, frente a las circunstancias que imponía la Burgfrieden, mantener la unidad del SPD requeria un fuerte disciplinamiento de sus miembros.

El 21 de diciembre de 1915, 33 miembros del SPD del Reichstag votaron en contra de nuevos créditos de guerra. La división en el seno del partido devino inevitable en enero de 1916. Luego de la expulsión de Karl Liebknecht y del resto de los diputados de la delegación socialdemócrata que habían votado en contra de los créditos, el ala izquierda agrupada 
alrededor del grupo Die Internationale (así llamado por el título de su órgano teórico), adopta en una conferencia nacional el 7 de enero de 1916, las tesis propuestas por Rosa Luxemburg desde la cárcel, Surge así, en el seno de la oposición a la política oficial del SPD, una división entre el ala centrista y el ala izquierda, constituyendo éstos últimos el grupo que seria conocido como Espartaco por las Spartakusbriefe o "Cartas de Espartaco" que publicó ilegalmente durante la guerra. Nucleado alrededor de Karl Liebknecht y Rosa Luxemburg, la Liga Espartaquista lanzó un llamado a la lucha de clases en plena Guerra Mundial.

A comienzos de 1917 el partido pone en práctica una verdadera purga de las minorías en su seno. Como consecuencia de ella, aún sin una resolución unánime al respecto, la oposición se escinde del SPD, conformando en Gotha en abril de 1917 el Partido Socialdemócrata Independiente (USPD: Unabhängige Sozialdemokratische Partei Deutschlands), bajo consignas antiburocráticas y anticentralistas. El nuevo partido constituía una amalgama de elementos revolucionarios -nucleados alrededor de la Liga Espartaquista- y de líderes centristas y aún revisionistas prominentes como Kautsky y Bernstein, que adhirieron al USPD con la intención de ejercer un contrapeso al grupo Espartaco y limitar su influencia. Las escisiones que surcaban a la oposición del SPD se reprodujeron en el nuevo partido: mientras que la derecha reformista del USPD se nucleó en torno a Karl Kautsky, la mayor parte de los dirigentes como Ledebour y Haase, oscilaron entre el espartaquismo y el reformismo.

\section{El fracaso de la revolución alemana}

Tras el estallido de la Revolución Rusa de febrero de 1917, las autoridades imperiales temen que la ola revolucionaria repercuta en Alemania. Con el apoyo de los líderes sindicales, pretenden desarmar a la clase obrera y contener la agitación de la Liga Espartaco a favor de la huelga de masas. En abril de 1917, con motivo de la reducción de la ración semanal de pan, 300 mil obreros se declaran en paro. Las autoridades militares calificaron a los huelguistas como "los peores enemigos entre nosotros" (Broué, 2005: 96). En consonancia con esta declaración, los sindicatos adoptaron un posicionamiento similar: "Las huelgas deben ser evitadas... sólo un aumento de la capacidad de resistencia de Alemania puede conducirnos a una paz rápida" (Broué, 2005: 96).

El peso de la dirigencia sindical en la escena política alemana, se tornó particularmente evidente a partir del ascenso de la combatividad obrera como resultado de la Revolución Rusa de octubre de 1917. Aunque en el USPD no hubo unanimidad sobre la postura a adoptar frente a la Revolución de Octubre, en enero de 1918, Espartaco convoca a la huelga 
general. En las asambleas generales previstas en todas las fábricas, los delegados revolucionarios obtienen aplastantes mayorias.

Durante el motín de los marineros de Kiel en octubre de 1918, los revolucionarios pertenecientes al ala izquierda del USPD organizan huelgas en apoyo a los marinos, presidiendo Consejos (Räte) en ciudades alemanas. El SPD, por su parte, se declara en contra de la utilización de métodos bolcheviques en Alemania y a favor de la democracia. Los dirigentes del viejo partido intentan asegurar que los sindicatos "empleen toda su autoridad para apaciguar a los obreros" (Broué, 2005: 131).

Luego de un interregno caracterizado por el poder dual, el Secretario General del SPD y presidente del Consejo Revolucionario de Delegados del Pueblo, Friedrich Ebert, "el Stalin de la Socialdemocracia" según el historiador Karl Schorske, acepta el cargo de Canciller del Reich. El 7 de noviembre de 1918, Ebert había advertido que si el emperador no abdicaba, la revolución social sería inevitable. Finalmente, el SPD consiguió desarticular el movimiento revolucionario gracias a la disolución de las reformas obtenidas luego de la Revolución de Noviembre y a la concentración del poder en la figura de Ebert. De este modo, las clases dominantes y el SPD -junto a sus sindicatos-, llevaron a cabo una contrarrevolución democrática que conservó tanto el aparato del Estado como el sistema capitalista.

Precisamente en el marco de su preocupación por desarticular la revolución social, el líder de la burocracia sindical, Carl Legien, junto a Hugo Stinnes, representante de las grandes industrias, firmaron el 15 de noviembre de 1918 un acuerdo que les otorgaba a los obreros la jornada de ochos horas, convenios colectivos de trabajo, el reconocimiento de los representantes de los sindicatos en cada lugar de trabajo y la elección de comités en todas las empresas industriales para supervisar junto a la patronal los convenios colectivos. Como contrapartida, los trabajadores debían entregar las armas, desarticular el movimiento de Consejos y renunciar a proclamarse como una alternativa al poder del aparato del Estado. El acuerdo Stinnes-Legien demostró que la burocracia sindical se posicionaba, a todas luces, en contra de la profundización y expansión de la revolución.

La inexistencia de un verdadero partido revolucionario también clausuró la posibilidad de fortalecer a los Consejos de obreros y soldados. Los líderes de la derecha del USPD, Haase y Robert Dittmann, adoptaron posiciones semejantes a las del SPD, contribuyendo a desarticular el movimiento consejista en Alemania. La Liga Espartaco, por el contrario, consideraba necesario permanecer en el interior del partido con el objetivo no aislarse del movimiento de masas.

El 15 de diciembre de 1918, en la Conferencia de Berlín del USPD, Rosa Luxemburg acusó a Haase de haber empujado a las masas a 
apoyar al gobierno de Ebert debido a su propia participación en el mismo. Luxemburg apeló a la "fe democrática" que parecía profesar el partido, para que se convocase a un Congreso extraordinario en el que los militantes decidirian si deseaban seguir formando parte de la coalición gobernante. La propuesta de la Liga Espartaquista fue rechazada, sellándose así la escisión en el seno del USPD. El 29 de diciembre de 1918, un Congreso de la Liga Espartaco resolvió formar una nueva organizión: el Partido Comunista Alemán (Espartaco) [Kommunistische Partei Deutschlands (Spartakus): KPD(S)]. El hecho de que el número de militantes del USPD que se une a ellos haya sido una minoría pequeña y que hayan prevalecido en su seno tendencias de extrema izquierda, hace cavilar a Luxemburg que la escisión podría haberse producido de manera prematura.

En enero de 1919 estalló la Revuelta Espartaquista en Berlín. Al cabo de una semana, el levantamiento es finalmente derrotado y Rosa Luxemburg y Karl Liebknecht, sumidos en la clandestinidad, son ejecutados el 15 de enero de 1919 por los Cuerpos Libres (Freikorps) -grupos armados paramilitares de extrema derecha-, en complicidad con el ala derecha del SPD, dirigida por Gustav Noske. A un mes de su creación, el KPD(S) pierde a sus líderes principales. La sangría continuó con la represión de la república de los consejos bávara, en la que es asesinado Eugen Leviné.

Ante la amenaza revolucionaria, la derecha, agrupada alrededor de los Cuerpos Libres decide avanzar para contener un nuevo brote revolucionario. Entre el 13 y el 17 de marzo de 1920, Wolfgang Kapp y Walther von Lüttwitz dirigen un golpe de estado contra el gobierno de Ebert. Cuando el putsch parecía un hecho consumado, Carl Legien, como presidente de la Federación Sindical Socialdemócrata, convocó a una huelga general por tiempo indeterminado. Con el país paralizado, los golpistas debieron desistir. La medida adoptada por la dirigencia sindical permitió la supervivencia de la República de Weimar, lo que implicaba preservar su propio aparato burocrático. No obstante ello, luego de la derrota del golpe de Estado, cientos de miles de obreros militantes concretaron su afiliación al KPD(S).

\section{Las 21 condiciones de la Comintern y el Congreso de Halle del USPD}

Del 19 de julio al 7 de agosto de 1920 se reúne el II Congreso de la Internacional Comunista, a los fines de precisar las condiciones de admisión de los partidos que desearan afiliarse a la Internacional Comunista. Algunos de los 21 puntos que se fijan reflejan la necesidad de la Internacional Comunista de protegerse frente a la amenaza que repre- 
sentan los elementos reformistas y social-pacifistas que aún sobrevivia en el seno de los partidos simpatizantes (Aricó, 1973: 109-110):

La Internacional comunista no puede admitir que reformistas reconocidos como Turati, Kautsky, Hilferding, Longuet, MacDonald, Modigliani y otros, tengan el derecho de ser considerados miembros de la III Internacional y estén representados en ella. (Ídem: 112)

Las condiciones de admisión a la Internacional Comunista reflejaban también una tenaz preocupación por resquebrajar los cimientos de la Internacional de Ámsterdam:

Todo partido perteneciente a la Internacional Comunista debe combatir con energía y tenacidad a la «Internacional» de los sindicatos amarillos fundada en Ámsterdam. Deben difundir constantemente en los sindicatos obreros la idea de la necesidad de la ruptura con la Internacional amarilla de Ámsterdam. (Ídem: 112)

Esta inquietud por el rol de los sindicatos se vio replicada durante el Congreso del USPD en la ciudad de Halle, durante el cual fueron discutidas las "2 1 condiciones" de admisión a la Comintern. Entre el 12 y el 17 de octubre de 1920, unos 392 delegados debatieron intensamente acerca del futuro del movimiento obrero alemán. Dos "partidos" estuvieron presentes en Halle, cada uno de ellos liderados por un "Secretario General": Otto Brass (izquierda) y Wilhelm Dittmann (derecha). Fueron dos las controversias fundamentales las que surcaron el Congreso. En primer lugar, la polémica sobre la conveniencia de formar parte de la Internacional Comunista. En segundo lugar, se discutiría una posible fusión con el $\mathrm{KPD}(\mathrm{S})$, teniendo en cuenta que implicaría la pérdida de autonomía del partido (Lewis y Lars, 2011: 8). A la postre, ambas mociones resultarian aprobadas.

Las facciones en pugna contaban con la presencia de líderes internacionales que habian llegado para afianzarlas, dos de ellos provenientes de Rusia: por un lado, Julius Martov, lider de los Mencheviques Internacionalistas, cercano a las posiciones del ala derecha del USPD, y por el otro, Grigory Zinoviev, Presidente del Comité Ejecutivo de la Internacional Comunista, quien, a pesar de sus debilidades como teórico y líder político, se distinguía por su habilidad como orador (Lewis y Lars, 2011: 29). En su discurso de cuatro horas, puso su conocimiento del alemán al servicio del ala izquierda del USPD. En un artículo suyo reseñando el Congreso, Zinoviev daba cuenta de las divisiones del 
partido y de los vínculos contrarrevolucionarios del ala derecha con la burocracia sindical:

Aunque Hilferding es el líder espiritual de la derecha del USPD, su líder práctico es el Sr. Dissmann. Este Dissmann es el actual Presidente del Sindicato Alemán de Trabajadores Metalúrgicos (...). Como Legien, es el santo patrón de la burocracia sindical contrarrevolucionaria de Alemania. De hecho, Dissmann ya es la mano derecha de Legien (...). Dissmann nos recuerda a Noske, dicen varios de nuestros camaradas de izquierda. (Lewis y Lars, 2011: 70-73)

Aludiendo a la defensa de la Internacional de Ámsterdam adoptada por la oposición durante el Congreso, Zinoviev advertía que "los líderes de derecha no tienen ni pueden tener otra base de masas que no sea la que le proporciona el grupo sindical" (Lewis y Lars, 2011: 72). El juicio de Zinoviev sobre esta fracción fue apodíctico: "Los lideres de derecha de los sindicatos alemanes constituyen el soporte principal de la contrarrevolución burguesa" (Lewis y Lars, 2011: 72).

\section{Conclusión}

En este trabajo hemos documentado el surgimiento y consolidación en Alemania de un estrato social -la burocracia sindical- que, aunque tuvo su origen en el seno del partido revolucionario de la clase obrera, con el tiempo adquirió privilegios e intereses que la llevaron a defender posiciones diametralmente opuestas a las tradiciones revolucionarias de esta clase. Dicho estrato social identifica, ya durante la controversia revisionista, a Rosa Luxemburg como su principal enemigo dentro del partido, y articula sus posiciones durante el debate sobre la huelga de masas, que tuvo lugar en la socialdemocracia alemana, como consecuencia del movimiento de masas ocasionado por la Revolución Rusa de 1905. Luego de la amalgama entre dicha casta y el funcionariado del partido -un proceso que no fue lineal ni exento de contradicciones, simbolizado por el acceso a la dirección del partido de Friedrich Ebert, el "Stalin de la socialdemocracia"-, la burocracia consigue marginar a los revolucionarios en el seno del movimiento obrero alemán e imponer dos politicas fundamentales:

1) Con el estallido de la Primera Guerra Mundial, el partido socialdemócrata alemán vota a favor de los créditos de guerra, es decir, abandona el internacionalismo proletario y lo reemplaza de hecho por el nacionalismo como su ideología oficial, argumentando que "a la hora del peligro, no puede traicionar a la patria". Esta adaptación al imperialismo lleva 
a la crisis de la Segunda Internacional y a la eventual conformación de la Internacional Comunista en 1919.

2) Durante la crisis revolucionaria que se abre en Alemania luego de la derrota de sus ejércitos a fines de la guerra y que se prolonga desde noviembre de 1918 hasta octubre de 1923, la burocracia sindical y partidaria consigue desarticular al movimiento consejista (Rätebewegung) que surge espontáneamente luego de la revuelta de los marineros de Kiel, e impedir la consolidación de un sistema soviético alemán, imponiendo en cambio una salida parlamentaria centrada en la asamblea constituyente reunida en Weimar, es decir, un modelo de contrarrevolución democrática. Ya Engels había predicho, en su carta a Bebel del 11 de diciembre de 1884, que, cuando llegase el momento de la revolución, "la democracia pura" se convertiria en "la última tabla de salvación de todo régimen burgués e incluso feudal. En momentos revolucionarios como esos, toda la masa reaccionaria se aferra a ella y la refuerza; todo lo que solía ser reaccionario pasa por democrático".

La obra histórica de la burocracia en Alemania, iniciada y dirigida por la dirección sindical, quedó reflejada con claridad meridiana en la evolución del término "socialdemocracia", que de denotar a un partido obrero revolucionario basado en un programa marxista - un partido que fue además la columna vertebral en torno a la cual se articuló la Segunda Internacional- pasó a designar, según el Diccionario de la Real Academia Española, una "Disidencia del marxismo, consistente sobre todo en rechazar la orientación revolucionaria de la lucha de clases, y en propugnar una vía democrática hacia el socialismo".

\section{Referencias}

Adler, Friedrich (ed.) (1954), Briefwechsel mit August Bebel und Karl Kautsky: Sowie Briefe von und An Ignaz Auer [et al.], Parteivorstand der Sozialistischen Partei Osterreichs, Wien: Verlag der Wiener Volksbuchhandlung.

Aricó, José (dir.) (1973), "Los cuatro primeros congresos de la Internacional Comunista", Cuadernos de Pasado y Presente, $\mathrm{n}^{\circ}$ 43, Siglo XXI: Buenos Aires.

Broué, Pierre (2005), The German Revolution 1917-1923 (1971), LeidenBoston: Brill.

Correspondenzblatt (1909), "Immer noch Civic Federation", Vorwärts, 23 de noviembre.

Cyphers, Christopher J. (2002), The National Civic Federation and the Making of a New Liberalism, 1900-1915, Westport, Conn.: Praeger.

Day, Richard B. y Gaido, Daniel (2007) Witnesses to Permanent Revolution: The Documentary Record, Leiden: Brill Academic Publishers.

Debs, Eugene (1905), Industrial Unionism: Speech delivered at Grand Cen- 
tral Palace, New York, Sunday, December 10, 1905, Chicago: Charles H. Kerr \& Company.

Die Neue Zeit (1900-1910), órgano del Partido Socialdemócrata Alemán, disponible en http://library.fes.de/nz/.

Evans, Richard (2005), La llegada del Tercer Reich, Barcelona: Península.

Fricke, Dieter (1959), "Der Reichsverband gegen die Sozialdemokratie von seiner Gründung bis zu den Reichstagswahlen von 1907", en Zeitschrift für Geschichtswissenschaft, 7: 237-280.

Friedemann, Peter (ed.) (1978), Materialien zum politischen Richtungsstreit in der deutschen Sozialdemokratie, 1890-1917, Frankfurt: Ullstein, 2 vols.

Gaido, Daniel (2003), "The American Worker and the Theory of Permanent Revolution: Karl Kautsky on Werner Sombart's Why Is There No Socialism in the United States?", Historical Materialism, 11, 4: 108-115.

- (2007), "El marxismo y la burocracia sindical. Karl Kautsky, Samuel Gompers y los Sindicatos Alemanes Libres”, La Bastilla, vol. 1, n 0, Córdoba: Ferreyra Editor, pp. 15-53.

Generalkommission der Gewerkschaften Deutschlands (1910), Sisyphusarbeit oder positive Erfolge? Beiträge zur Wertschätzung der Tätigkeit der deutschen Gewerkschaften, Berlin: Generalkommission der Gewerkschaften Deutschlands.

Gompers, Samuel (1910), Labor in Europe and America: Personal Observations from an American Viewpoint of Life and Conditions of Working Men in Great Britain, France, Holland, Germany, Italy, etc., Nueva York: Harper \& Brothers.

Grunenberg, Antonia (ed.) (1970), Die Massenstreikdebatte: Beiträge von Parvus, Rosa Luxemburg, Karl Kautsky und Anton Pannekoek Frankfurt: Europaische Verlagsanstalt.

Hillquit, Morris (1971), History of Socialism in the United States (1910), Nueva York: Dover Publications.

Kaufman, Stuart B., Peter J. Albert y Grace Palladino (eds.) (1999), The American Federation of Labor under Siege, 1906-1909: The Samuel Gompers Papers, vol. 7: The American Federation of Labor under Siege, 1906-1909, Urbana: University of Illinois Press.

Kautsky, Karl (1909), The Road to Power: Political Reflections on Growing into the Revolution, Chicago: Bloch, en http://www.marx.org/archive/ kautsky/1909/power/index.htm

Kipnis, Ira (1952), The American Socialist Movement, 1897-1912, Nueva York: Columbia University Press.

Laschitza, Annelies (1969), Deutsche Linke im Kampf für eine demokratische Republik : der Kampf der deutschen Linken für eine demokratische Republik und die Anwendung des politischen Massenstreiks in Deutschland; zur Entwicklung der deutschen Linken als politisch-ideologische Strömung in der deutschen Sozialdemokratie (1909-1910), Berlín: Dietz. 
Legien, Carl (1914), Aus Amerikas Arbeiterbewegung, Berlin: Verlag der Generalkommission der Gewerkschaften Deutschlands.

Lenin, Vladimir I. (1970), "What Should Not Be Copied from the German Labor Movement" (1914), en Collected Works, Volumen 20, pp. 254-258, Moscú: Foreign Languages Publishing House, en http:/ /www.marx.org/ archive/lenin/works/1914/apr/00.htm

- (1972), The State and Revolution (1917), en Collected Works, Volumen 25, Moscú: Foreign Languages Publishing House, en http:/ /www.marx.org/ archive/lenin/works / 1917/staterev/index.htm

- (1974), "In America" (1912), en Collected Works, Volumen 36, Moscú: Foreign Languages Publishing House. Reimpreso en Lenin on the United States: Selected Writings, Nueva York: International Publishers, 1970, pp. 56-57, en http://www.marx.org/archive/lenin/works/1912/dec/07.htm

Lewis, Ben y Lars, T. Lih (2011), Martov and Zinoviev: Head to head in Halle, Londres: November Publications.

Luxemburg, Rosa (1970), Reform or Revolution (1910), en Mary-Alice Waters (ed.), Rosa Luxemburg Speaks, Nueva York: Pathfinder, en http://www. marx.org/archive/luxemburg/1900/reform-revolution/index.htm

- (1972a), 'Die Debatten in Köln' (1905), Sächsiche Arbeiter-Zeitung, Nr. 140 (21 de junio de 1905), reimpreso en Gesammelte Werke, Berlin: Dietz Verlag, volumen 1, parte 2: 580-586.

- (1972b), "Parteitag der Sozialdemokratischen Partei Deutschlands vom 17. bis 23. September 1905 in Jena" (1905), Gesammelte Werke, Berlin: Dietz Verlag, volumen 1, parte 2: 595-604.

- (1972c), 'Was Weiter?' (1910), en Dortmunder Arbeiterzeitung, 14-15 de marzo de 1910, reimpreso en Rosa Luxemburg, Gesammelte Werke, Berlin: Dietz Verlag, volumen 2: 289-299.

- (1973a), 'Parteitag der Sozialdemokratischen Partei Deutschlands vom 23. bis 29. September 1906 in Mannheim' (1906), Gesammelte Werke, Berlin: Dietz Verlag, volumen 2: 171-176.

- (1973b), 'Die zwei Methoden der Gewerkschaftspolitk' (1907), Die Neue Zeit, 25, 1: 134-137, reimpreso en Gesammelte Werke, Berlín: Dietz Verlag, volumen 2: 182-187.

- (1973c), 'Die Theorie und die Praxis' (1910), Die Neue Zeit, 28, 2: 564-578, 626-642; reimpreso en Gesammelte Werke, Berlin: Dietz Verlag, volumen 2: 378-420.

- (1973d), 'Das Offiziösentum der Theorie' (1913), Die Neue Zeit, 31, 2, septiembre de 1913: 828-843; reimpreso en Gesammelte Werke, Berlin: Dietz Verlag, volumen 2: 300-321.

- (2006), La crisis de la Socialdemocracia (1916), Madrid: Fundación Federico Engels.

Mandel, Bernard (1963), Samuel Gompers: A Biography, Yellow Springs, Ohio: Antioch Press.

Salvadori, Massimo (1979), Karl Kautsky and the Socialist Revolution, 18801938, Londres: NLB. 
Schneider, Michael (1991), A Brief History of the German Trade Unions, Bonn: J. H. W. Dietz.

Schorske, Carl E. (1970), German Social Democracy, 1905-1917: The Development of the Great Schism, Nueva York: Russell \& Russell.

Sombart, Werner (1976), Why Is There No Socialism in the United States? (1906), Londres: Macmillan.

Stern, Leo (ed.) (1961), Die russische Revolution von 1905-1907 im Spiegel der deutschen Presse, Berlín: Rütten \& Loening, 5 vols.

Trautmann, William E. (ed.) (1905), Proceedings of the Founding Convention of the Industrial Workers of the World: Founded at Chicago, June 27-July 8, 1905, Nueva York, N.Y.: New York Labor News Company, en http://www. marxists.org/history/usa/unions/iww/1905/convention/index.htm

Trotsky, León (1973), "Hands off Rosa Luxemburg", en Writings 1932, Nueva York: Pathfinder Press.

Varain, Heinz Josef (1956), Freie Gewerkschaften, Sozialdemokratie und Staat: Die Politik der Generalkommission unter der Führung Carl Legiens (1890-1920), Düsseldorf: Droste.

Waldenberg, Marek (1980), Il papa rosso: Karl Kautsky, trad. de Maria di Salvo, Roma: Editori Riuniti, 2 vols.

Zerzan, John (1974), 'Understanding the Anti-Radicalism of the National Civic Federation', International Review of Social History, 19: 194-210.

Zinoviev, Grigory (1970), 'La II ${ }^{\circ}$ Internationale et le problème de la guerre. Renonçons-nous a notre héritage (octobre 1916)' (1916), en Lenine, N. y Zinoviev, G., Contre le courant, París: F. Maspero, 2 volúmenes.

$* * *$

Resumen: Este trabajo reseña las polémicas llevadas a cabo por el ala revolucionaria de la socialdemocracia alemana contra el reformismo de los dirigentes sindicales ligados al partido, particularmente en torno a la consigna de la huelga política de masas, levantada como resultado de la Revolución Rusa de 1905. El artículo describe también el rol de dichos dirigentes en la conformación del ala de centro liderada por Karl Kautsky a partir de 1910, en el abandono del internacionalismo en 1914 y en la consolidación de un régimen de contrarrevolución democrática en Alemania, a partir de noviembre de 1918. Se demuestra cómo la burocracia sindical y partidaria desarticuló políticamente a la clase obrera alemana, sentando así las bases para dos de las más grandes derrotas históricas del proletariado mundial: el colapso de la Segunda Internacional y el fracaso de la Revolución Alemana de 1918-1923.

Palabras clave: bucrocracia sindical - socialdemocracia alemana - marxismo

Abstract: This paper reviews the polemics carried out by the revolutionary wing of German Social Democracy against the reformism of the trade union leaders linked to the SPD, particularly around the slogan of the political mass strike -a watchword raised as a result of the Russian Revolution of 1905. The article also 
describes the role of the union leaders in shaping the center wing led by Karl Kautsky after 1910, in the abandonment of internationalism in 1914 and in the consolidation of democratic counter-revolution in Germany from November 1918 onwards. It shows how the union and party bureaucracy distorted the formerly revolutionary political outlook of the German working class, thus laying the groundwork for two of the greatest historical defeats of the world proletariat: the collapse of the Second International and the failure of the German Revolution of 1918-1923.

Keywords: trade union bureaucracy - German social democracy - Marxism

Recepción: 16 de mayo de 2012 - Aprobación: 29 de junio de 2012 